Fountain Journal of Natural and Applied Sciences: 2016; 5(1): 1 - 11
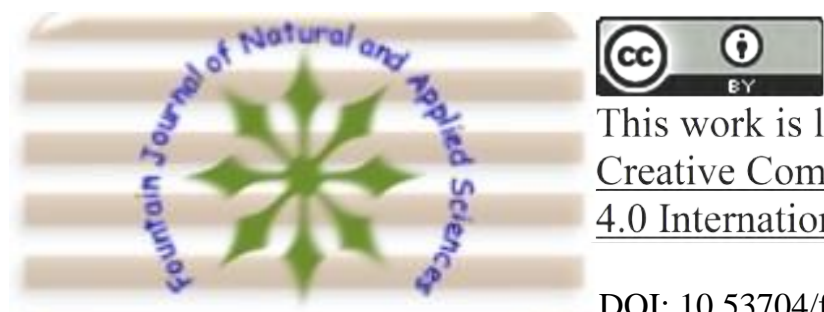

This work is licensed under Creative Commons Attribution 4.0 International License.

DOI: 10.53704/fujnas.v5i1.48

A publication of College of Natural and Applied Sciences, Fountain University, Osogbo, Nigeria.

Journal homepage: www. fountainjournals.com

ISSN: 2354-337X (Online), 2350-1863 (Print)

\title{
Evaluation of Calabash Chalk Effects on Selected Enzymes and Histology of Rat Liver and Kidney
}

\author{
${ }^{\star 1}$ Nafiu, M. O., ${ }^{2}$ Alli, L. A. and ${ }^{3}$ Aniah, J. A. \\ . ${ }^{1}$ Department of Biochemistry, Faculty of Life Sciences, University of Ilorin, Nigeria. olumikail@gmail.com \\ ${ }^{2}$ Department of Medical Biochemistry, Faculty of Basic Medical Sciences, University of Abuja, Nigeria. adewalealli@gmail.com \\ ${ }^{3}$ Department of Anatomical Sciences, Faculty of Basic Medical Sciences, University of Abuja, Nigeria. akayaniah@yahoo.com
}

\begin{abstract}
Consumption of geophagic material (Calabash chalk or Nzu) as a remedy for morning sickness is a common practice among pregnant women in Eastern part of Nigeria with attendant possible health implication. This study is designed to evaluate the effects of calabash chalk on some enzymes and histopathology of rat liver and kidney. Thirty-five albino rats were randomly divided into seven groups of 5 rats each. Group A received $10 \mathrm{ml} / \mathrm{kg}$ body weight of distilled water, groups B, D and F received 150,250 and $500 \mathrm{mg} / \mathrm{kg}$ b.w of unprocessed calabash chalk respectively, while groups C, E and $G$ were administered 150,250 and $500 \mathrm{mg} / \mathrm{kg}$ b.w of processed calabash chalk respectively. Treatments were administered orally for 28 days. On 29th day, all animals were sacrificed; assays of AST, ALT, GGT and ALP were carried out, followed by liver and kidney histology. Significant increase in activity of aspartate aminotransferase (AST) was observed in the serum, at $500 \mathrm{mg} / \mathrm{kg}$ in liver and 250 and $500 \mathrm{mg} / \mathrm{kg}$ in kidney except at $500 \mathrm{mg} / \mathrm{kg}$ for the unprocessed. However, activity of alanine aminotransferase (ALT) in serum, liver and kidney were unaffected. Significant reduction was observed in gamma-glutamyl transeferase (GGT) activity only at $500 \mathrm{mg} / \mathrm{kg} \mathrm{b.w} \mathrm{for} \mathrm{the}$ processed while all doses produced reduction in alkaline phosphatase (ALP) activity. Histological changes, such as central vein dilatation in the liver and interstitial fibrosis with areas of necrosis were observed in the kidneys. Hence, consumption of calabash chalk may produce undesirable effect on the biological system as represented by the results and therefore must be discouraged.
\end{abstract}

Keywords: Calabash chalk, enzymes, geophagia, histopathology, Nzu.

\section{Introduction}

Consumption of clay and cravings for other non-nutritious substances, referred to as geophagia, is a practice that has been reported in different geographical regions across racial and cultural boundaries. Geophagia has been reported in Georgia (USA), UK and Canada especially among immigrants from West Africa and South Asia (FSA, 2003; Dean et al., 2004; Health Canada, 2007). In Nigeria, it is commonly observed among pregnant women in the Eastern part of the country especially among the Igbo-speaking culture. Geophagia is a compulsive

*Corresponding author: 2348054208511

Email address: olumikail@gmail.com 
eating of earthy substances such as sand, soil and clay (Abrahams et al., 2013). It is elated characterized by abnormal cravings for non-food substances such as clay, corn starch and baking soda (Alexander et al., 2002; Abrahams et al., 2013). Pregnant women who traditionally eat substances like clay, corn starch and baking soda believe that such substances prevent vomiting, leg swelling and help babies to thrive (Mcloughlin, 2002). In parts of Africa and villages in India, clay consumption is commonly associated with pregnant women who consume earth materials to alleviate the symptoms of morning sickness (Abrahams et al., 2013). Aside from its consumption by pregnant women, clay such as montmorillonite, has cation-exchange capacity and is used as a component of anti-diarrheal medication (Ferell, 2008). Some bentonite clays have the potential of chelating heavy metals (Ferell, 2008) and also reducing the toxic effects of aflatoxins (Williams et al., 2009). Clay also serves as reservoir of organic substances and minerals that may be beneficial or cause adverse reactions when consumed (BisiJohnson et al., 2010).

Calabash chalk is structurally similar to aluminium silicate hydroxide, which is a member of the kaolin clay group with the formula $\mathrm{Al}_{2} \mathrm{Si}_{2} \mathrm{O}_{5}(\mathrm{OH})_{4}$ (Abrahams et al., 2013).

Geophagical clay consumed by pregnant women in Nigeria is called calabash chalk. It is also known, according to language/location in Nigeria, as Calabar stone, Calabash clay, Ndom, Nzu or Ulo (Abrahams et al., 2013).

The processed calabash chalk is prepared using clay, wood-ash and salt. This mixture is moulded and then heated in a hot furnace to reduce the risks of contamination from pathogens. Calabash chalk is available in a variety of forms including powder and moulded solids.

The aim of this study was to analyze the mineral composition of calabash chalk and investigate any adverse effect on some liver and kidney enzymes after repeated administration of calabash chalk to rats for 28 days. This will provide information on the possible effects of repeated consumption of calabash chalk on liver and kidney of pregnant women in our local communities related to Pica which is eating disorder

\section{Materials and Methods}

\section{Calabash Chalk}

This study was conducted in the Department of Biochemistry, Faculty of Life Sciences, University of Ilorin, Nigeria, during March - August 2014. Calabash chalks (Processed and unprocessed) were obtained from "Kubwa village" market, Kubwa, Abuja, Nigeria.

\section{Laboratory Animals}

Thirty-five healthy albino rats (Rattus novergicus) of both sexes weighing $170 \pm 20 \mathrm{~g}$ were obtained from the Animal Holding Unit, Department of Biochemistry, University of Ilorin, Nigeria. All the animals were kept in plastic cages that provided access to rat pellets (Bendel Feeds and Flour Mills Ltd., Ewu, Nigeria) and clean water ad libitum. This study was approved by the Animal Ethics Committee of Department of Biochemistry, University of Ilorin, Nigeria. Handling of animals was done following the guidelines of the Committee for the Purpose of Control and Supervision of Experiments on Animals (CPCSEA).

\section{Reagents}

Aspartate aminotransferase (AST), alanine aminotransferase (ALT), and gamma glutamyl transeferase (GGT) were products of Randox Laboratories Ltd., United Kingdom. Paranitrophenyl phosphate (PNPP) was a product of Santa Cruz Biotechnology, Texas, United States. Other reagents used which were of analytical grades were prepared with distilled water and kept in clean airtight reagent bottles

\section{Preparation of Aqueous Calabash Chalk}

Calabash chalk (processed and unprocessed) weighing $400 \mathrm{~g}$ was ground into powder with ceramic mortar and pestle and sieved through a nylon mesh. To $200 \mathrm{~g}$ of each powdered calabash chalk (processed and unprocessed), $1000 \mathrm{ml}$ of distilled water was 
added and stirred continuously for 3 hours at room temperature. The suspension was then filtered using Whatman filter paper to remove debris. The filtrate was evaporated in a water bath at $40^{\circ} \mathrm{C}$ to obtain $20 \mathrm{~g}$ of processed and $15 \mathrm{~g}$ of unprocessed calabash chalk. The required doses of 150, 250 and $500 \mathrm{mg} / \mathrm{kg}$ body weight were prepared from this residue daily for twenty-eight days using distilled water.

\section{Mineral Analysis}

Mineral component of processed and unprocessed calabash chalk was analyzed using atomic absorption spectrophotometer as described by the Association of Official Analytical Chemists (Dean et al., 2004). Structural properties of the calabash chalk were analyzed using multipurpose $X$ ray diffractometer (MPD Pan-analytical Cubix-3) Netherlands.

\section{Acute toxicity study}

The acute toxicity of the aqueous extract of calabash chalk was evaluated in rats following the Organisation for Economic Cooperation and Development (OECD) Guidelines 423 (OECD, 2001). Four groups, of three female rats pergroup, received the aqueous extract orally, at doses of 50,300 and $2000 \mathrm{mg}$ extract/ $\mathrm{kg}$ body weight respectively, while the control group received $10 \mathrm{ml} / \mathrm{kg}$ b.w of distilled water. Animals were observed individually after dosing for signs of toxicity (changes in skin, fur, respiration, motor activity) once during the first 30 minutes, periodically during the first $24 \mathrm{~h}$ and daily thereafter for 14 days. The $L D_{50}$ value obtained from this study was used in estimating the various graded doses that were used in the sub- acute study.

\section{Animal Grouping and 28 days administration of Calabash Chalk}

Thirty-five albino rats were randomly divided into seven groups ( $A-G)$ of 5 rats each. Group $A$ (control) received $10 \mathrm{ml} / \mathrm{kg}$ body weight of distilled water, groups $B, D$ and $F$ received 150 ,
250 and $500 \mathrm{mg} / \mathrm{kg} \mathrm{b.w} \mathrm{of} \mathrm{unprocessed}$ calabash chalk respectively, while groups $C, E$ and $G$ were administered 150,250 and $500 \mathrm{mg} / \mathrm{kg}$ b.w of processed calabash chalk respectively. All the animals in each group were administered extract and distilled water (control) orally for 28 consecutive days using oral cannula (OECD, 2006).

\section{Preparation of serum and Tissue Homogenates}

On the 29th day, the rats were individually weighed and then anaesthetized with diethyl ether. The animals were dissected to expose the heart and blood was collected by cardiac puncture into labelled plain tubes. The blood was centrifuged at $3000 \mathrm{rev} / \mathrm{min}$ for 10 minutes to obtain serum which was collected using a Pasteur pipette into clean, dry sample bottles and kept in refrigerator until required for assay.

The liver and kidney were also removed after dissection of the animals. The liver and kidney were cleaned of blood stains, weighed and a portion (1g) of the tissue was homogenized in $0.25 \mathrm{M}$ sucrose solution $(1: 5 \% \mathrm{w} / \mathrm{v})$. The homogenates were centrifuged at $3500 \mathrm{rev} / \mathrm{min}$ for 15 minutes to obtain supernatants which were collected into specimen bottles and kept frozen before being used for various analyses.

\section{Determination of enzyme activities}

Aspartate aminotransferase and alanine aminotransferase activities were determined using standard methods described by Reitman and Frankel (1957) as mo dif ied by Schmidt and Schmidt (1963). Activity of alkaline phosphatase was determined using the methods of Wright et al. (1972) and gamma glutamyl transferase activity determined following the method described by Szasz (1969).

\section{Preparation of organs for histological analysis}

The organs were prepared for histopathological analysis according to the procedure described by Krause (2001). They were stained with hematoxylin and eosin (H\&E) and 
the photomicrographs were captured at $\times 400$ using presto! image Folio package.

\section{Statistical Analysis}

Data were expressed as the means \pm SD of five determinations. Statistical analysis was carried out using one-way Analysis of Variance (ANOVA) and Duncan's Multiple Range Test. The data were considered significant at $p<$ 0.05 .

\section{Results}

The mineral constituents of processed and unprocessed calabash chalk are shown in table 1. Both processed and unprocessed samples contained similar mineral content but the processed sample contained higher amount of each of these minerals (except iron and phosphorus) than unprocessed calabash chalk. Also, low level of zinc was detected in the unprocessed sample but absent in the processed calabash chalk. Heavy metals such as arsenic, chromium and lead were not detected in both samples of calabash chalk.

The administration of processed and unprocessed samples of calabash chalk to rats produced significant increase $(p<0.05)$ in AST activity in the serum at all the doses administered when compared to the control. Significant increases, compared with the control $(p<0.05)$, were obtained at all doses in the kidney except for $150 \mathrm{mg} / \mathrm{kg} \mathrm{b.w}$ while increases in the liver were significant ( $p<$ 0.05 ) at $500 \mathrm{mg} / \mathrm{kg}$ b.w. Reductions were, however, noted at $150 \mathrm{mg} / \mathrm{kg}$ for both processed and unprocessed calabash chalk in the liver (Table 2).

The administration of both samples of calabash chalk shows no significant effect ( $p$ > 0.05 ) in the ALT activity in serum, liver and kidney at all the doses administered (Table 3).

The administration of processed and unprocessed calabash chalk had no significant ( $p>0.05$ ) effect on GGT activity in the rat serum at all doses compared with the control except at $500 \mathrm{mg} / \mathrm{kg}$ b.w where significant $(p<0.05)$ reduction was observed (Figure 1 ).

There were significant(p $<0.05)$ reductions in serum ALP activities of rats at all administered doses of the processed and unprocessed calabash chalk compared to the control (Figure 2). Doses of 250 and $500 \mathrm{mg} / \mathrm{kg}$ b.w of calabash chalk produced visible changes in the kidneys of rats ranging from, focal necrosis (Plates 4a, 4b, 5a and 5b); interstitial fibrosis (Plate $4 a$ ) and mesengial proliferation (Plate 4b). Administration of 250 and $500 \mathrm{mg} / \mathrm{kg}$ b.w of calabash chalk caused visible changes in the liver of rats such as central vein dilatation and cellular hyperplasia (Plates 8a, 8b, 9a and 9b).

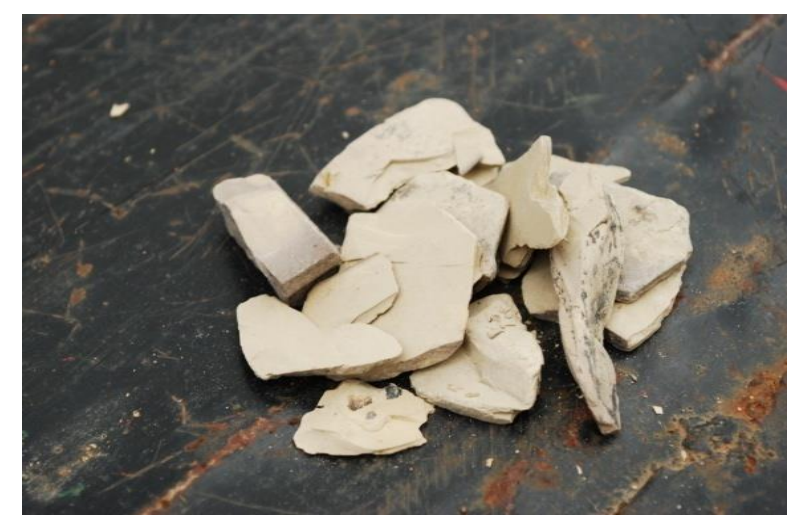

Plate 1: Sample of calabash chalk (Nzu) (a) Unprocessed (b) Processed Source: Alexander et al. (2002) 
Table 1: Mineral constituents of Calabash chalk

\begin{tabular}{lll}
\hline Minerals & Unprocessed $(\mathrm{mg} / \mathrm{g})$ & Processed $(\mathrm{mg} / \mathrm{g})$ \\
\hline Calcium & 256.8 & 265.0 \\
Magnesium & 186.9 & 727.8 \\
Potassium & 98.6 & 109.4 \\
Sodium & 52.3 & 85.6 \\
Copper & 1.43 & 2.13 \\
Manganese & 1.20 & 1.33 \\
Iron & 0.51 & 0.21 \\
Phosphorus & 0.51 & 0.21 \\
Zinc & 0.19 & Not detected \\
Arsenic & Not detected & Not detected \\
Chromium & Not detected & Not detected \\
Lead & Not detected & Not detected \\
\hline
\end{tabular}

Table 2: Activity of aspartate aminotransferase in tissues of rats administered calabash chalk

\begin{tabular}{lll|ll|rl}
\hline \multirow{2}{*}{$\begin{array}{l}\text { Dose } \\
\text { (mg/kg }\end{array}$} & \multicolumn{2}{c}{ Serum $(U / L)$} & \multicolumn{2}{c}{ Liver $(U / L)$} & Kidney (U/L) \\
b.wt) & processed & unprocessed & Processed & unprocessed & processed & unprocessed \\
\hline Control & $28.79 \pm 7.69^{\mathrm{a}}$ & $28.79 \pm 7.69^{\mathrm{a}}$ & $14.10 \pm 3.36^{\mathrm{c}}$ & $14.10 \pm 3.36^{\mathrm{c}}$ & $11.10 \pm 0.46^{\mathrm{c}}$ & $11.10 \pm 0.46^{\mathrm{c}}$ \\
150 & $52.99 \pm 7.26^{\mathrm{b}}$ & $58.44 \pm 0.06^{\mathrm{b}}$ & $9.04 \pm 1.27^{\mathrm{b}}$ & $9.97 \pm 1.57^{\mathrm{b}}$ & $10.36 \pm 0.72^{\mathrm{c}}$ & $15.56 \pm 1.35^{\mathrm{b}}$ \\
250 & $63.88 \pm 0.03^{\mathrm{b}}$ & $71.50 \pm 3.19^{\mathrm{b}}$ & $13.50 \pm 0.84^{\mathrm{c}}$ & $13.65 \pm 3.01^{\mathrm{c}}$ & $14.61 \pm 2.49^{\mathrm{b}}$ & $18.62 \pm 4.38^{\mathrm{b}}$ \\
500 & $50.52 \pm 0.09^{\mathrm{b}}$ & $71.65 \pm 4.01^{\mathrm{b}}$ & $19.66 \pm 0.17^{\mathrm{d}}$ & $16.18 \pm 3.72^{\mathrm{c}}$ & $15.69 \pm 0.01^{\mathrm{b}}$ & $13.54 \pm 0.01^{\mathrm{b}}$ \\
\hline
\end{tabular}

Values carrying superscripts different from the controls for each parameter down the columns are significantly different $(p<0.05)$. Data are means \pm SD of 5 replicates.

Table 3: Activity of alanine aminotransferase in tissues of rats administered calabash chalk

\begin{tabular}{lllll|ll}
\hline \multirow{2}{*}{$\begin{array}{l}\text { Dose } \\
\text { (mg/kg }\end{array}$} & \multicolumn{2}{c}{ Serum (U/L) } & \multicolumn{2}{c}{ Liver (U/L) } & \multicolumn{2}{c}{ Kidney (U/L) } \\
\cline { 2 - 7 } b.wt) & processed & unprocessed & Processed & unprocessed & processed & Unprocessed \\
\hline Control & $10.81 \pm 2.41^{a}$ & $10.81 \pm 2.41^{a}$ & $10.92 \pm 2.26^{a}$ & $10.92 \pm 2.26^{a}$ & $10.16 \pm 0.49^{a}$ & $10.16 \pm 0.49^{a}$ \\
150 & $11.67 \pm 1.57^{a}$ & $11.50 \pm 0.12^{a}$ & $10.72 \pm 1.67^{a}$ & $10.13 \pm 1.57^{a}$ & $8.68 \pm 0.82^{a}$ & $10.71 \pm 1.10^{a}$ \\
250 & $11.67 \pm 1.17^{a}$ & $10.57 \pm 0.59^{a}$ & $10.40 \pm 2.86^{a}$ & $10.84 \pm 1.27^{a}$ & $10.70 \pm 0.90^{a}$ & $9.51 \pm 0.14^{a}$ \\
500 & $9.40 \pm 1.57^{a}$ & $8.72 \pm 1.10^{a}$ & $12.26 \pm 1.12^{a}$ & $12.03 \pm 1.22^{a}$ & $9.76 \pm 0.01^{a}$ & $10.99 \pm 0.38^{a}$
\end{tabular}

Values carrying superscripts different from the controls for each parameter down the columns are significantly different $(p<0.05)$. Data are means \pm SD of 5 replicates 


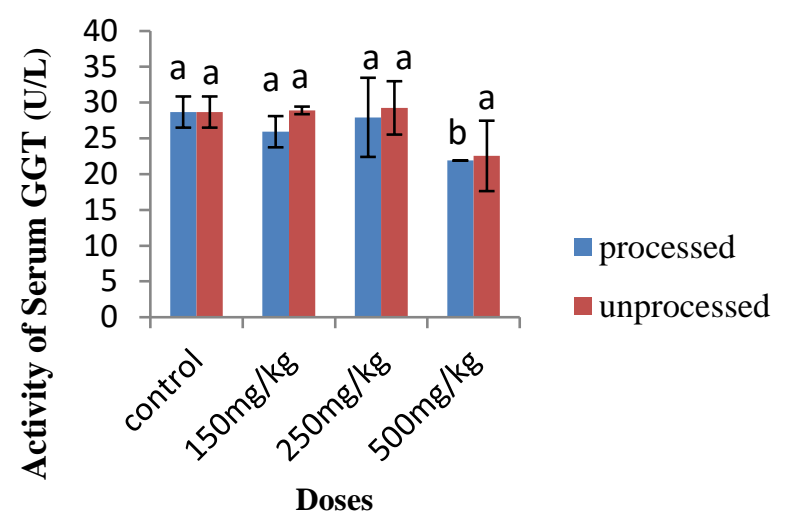

Figure 1: Activity of serum gamma-glutamyl transferase (GGT) in rats administered processed and unprocessed Calabash chalk

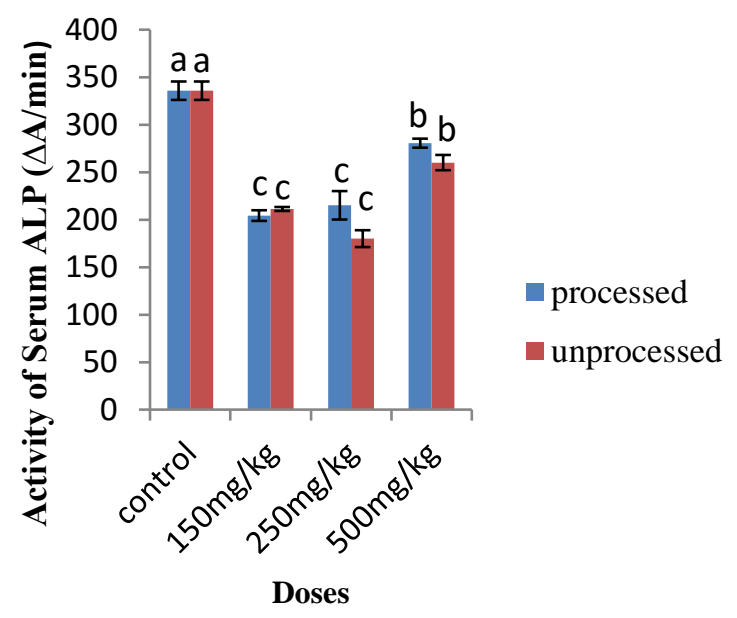

Figure 2: Activity of serum alkaline phosphate (ALP) in rats administered processed and unprocessed Calabash Chalk

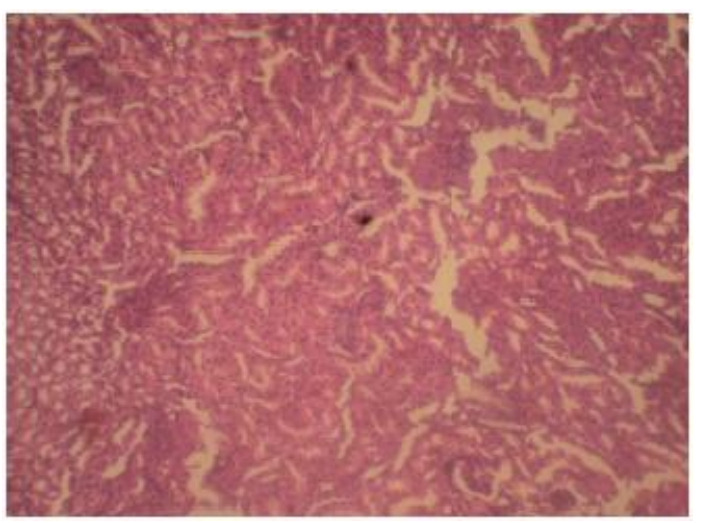

Plate 2: Photomicrograph of control rat kidney ( $\times 100)$ showing normal renal parenchyma and cells

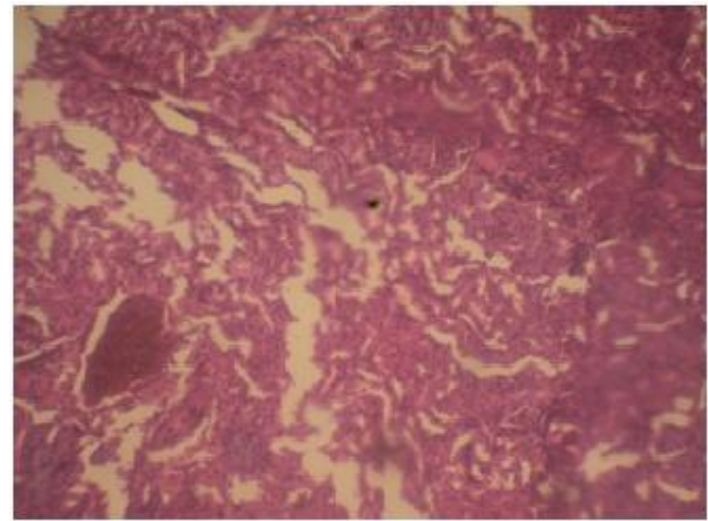

Plate 3a: Photomicrograph of kidney of rat administered $150 \mathrm{mg} / \mathrm{kg}$ b.w of processed Calabash chalk $(\times 100)$ showing normal renal structure.

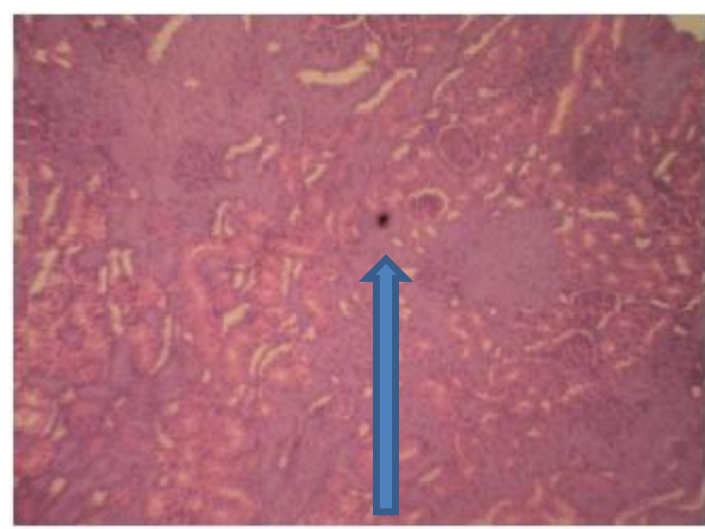

Plate 3b: Photomicrograph of kidney of the rat administered $150 \mathrm{mg} / \mathrm{kg}$ b.w of unprocessed Calabash chalk $(\times 100)$. Mesengial proliferation with normal renal architecture is observed.

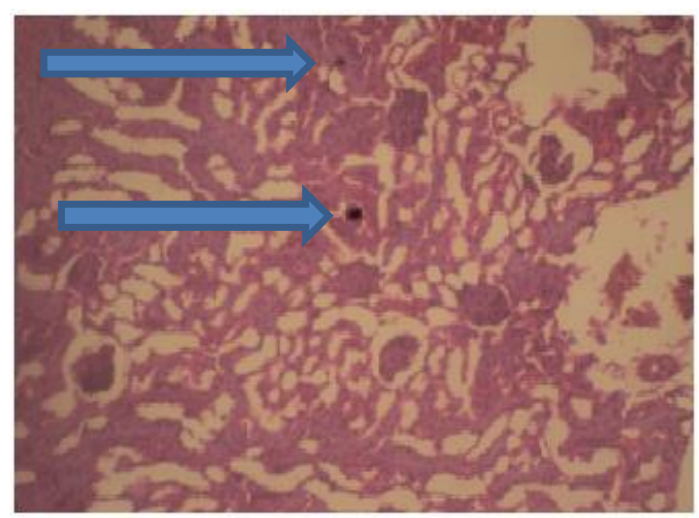

Plate 4a: Photomicrograph of kidney of rat administered $250 \mathrm{mg} / \mathrm{kg}$ b.w of processed Calabash chalk (x100). Areas of necrosis, and mild interstitial fibrosis are seen. 


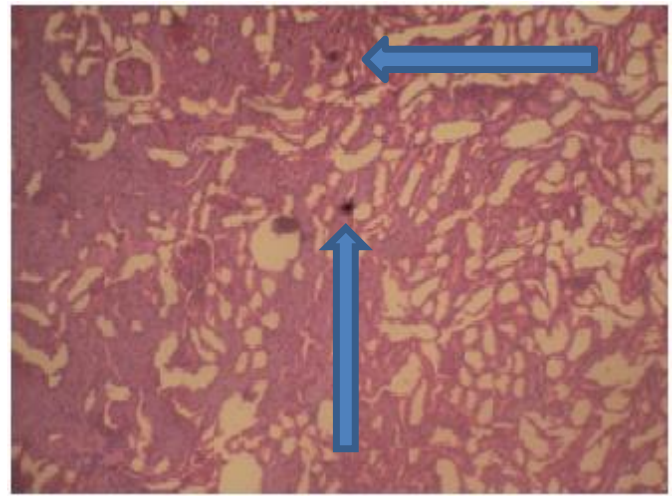

Plate 4b: Photomicrograph of kidney of rat administered $250 \mathrm{mg} / \mathrm{kg}$ b.w of unprocessed Calabash chalk $(\times 100)$. Mild mesengial proliferation and scanty areas of necrosis are seen.

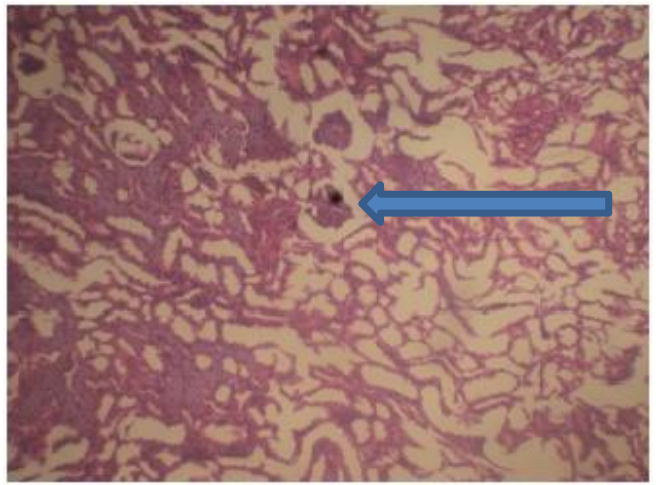

Plate 5a: Photomicrograph of kidney of rat administered $500 \mathrm{mg} / \mathrm{kg}$ b.w of processed Calabash chalk $(\times 100)$. Distortion of renal architecture with focal areas of fibrosis is observed.

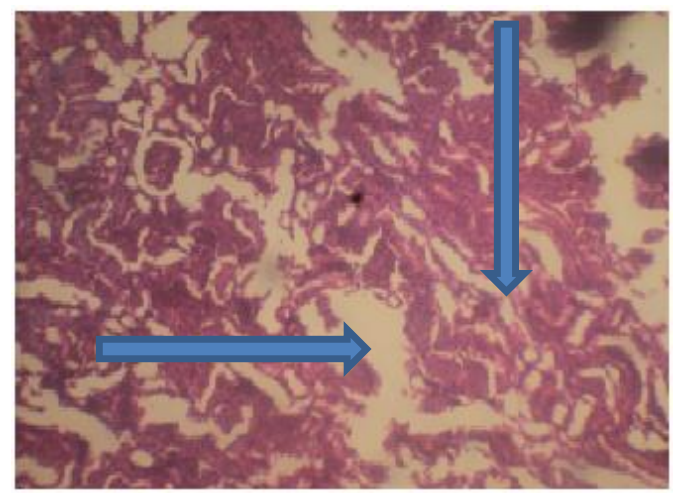

Plate 5b: Photomicrograph of kidney of rat administered $500 \mathrm{mg} / \mathrm{kg}$ b.w of unprocessed Calabash chalk $(\times 100)$. Distortion of renal architecture and medullary rays with scanty areas of necrosis are observed.

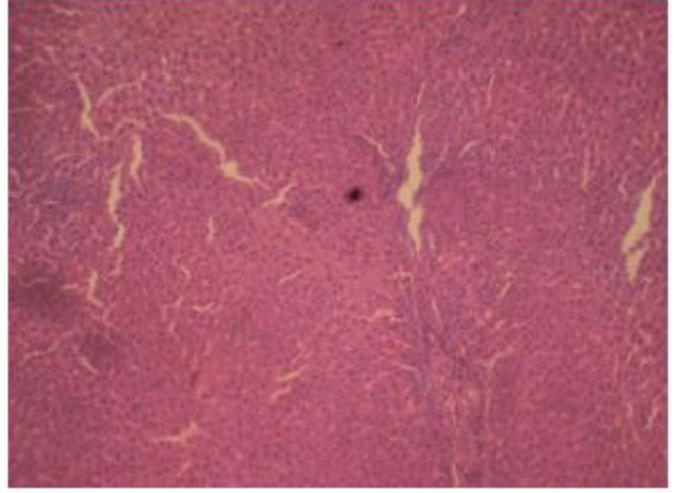

Plate 6: Photomicrograph of control rat liver (×100). Normal structure and cells.

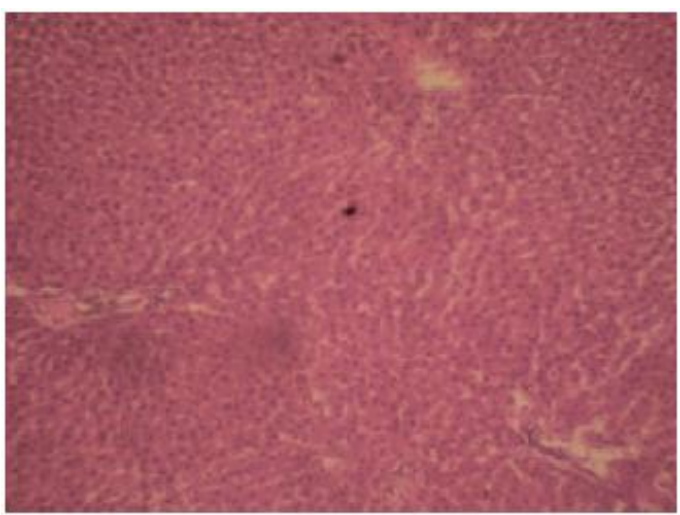

Plate 7a: Photomicrograph of liver of rat administered $150 \mathrm{mg} / \mathrm{kg}$ b.w of processed Calabash chalk (x100). Normal lobular architecture with normal hepatocytes.

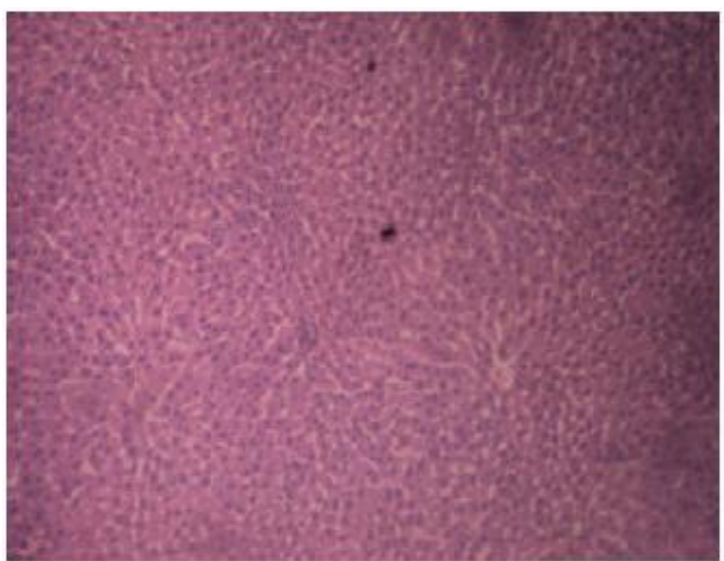

Plate 7b: Photomicrograph of liver of rat administered $150 \mathrm{mg} / \mathrm{kg}$ b.w of unprocessed Calabash chalk $(\times 100)$. Normal lobular architecture, normal hepatocytes and numerous nuclei. 


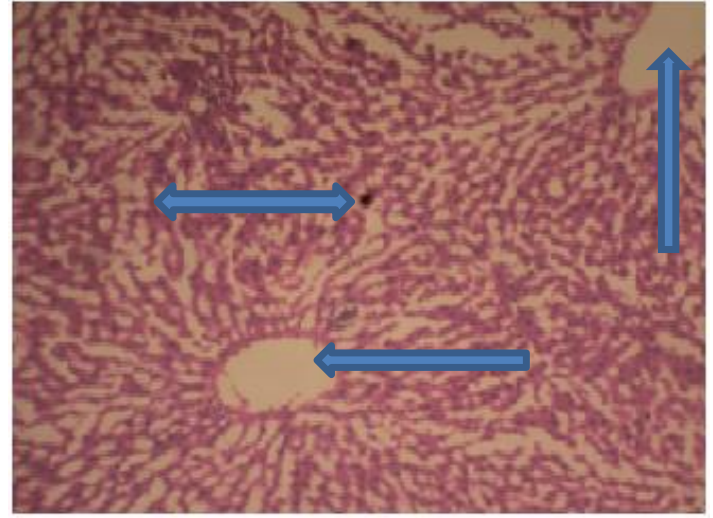

Plate 8a: Photomicrograph of liver of rat administered $250 \mathrm{mg} / \mathrm{kg}$ b.w of processed Calabash chalk $(\times 100)$. Mild dilatation of the central vein and sinusoids, with fragmentation of the hepatocytes.

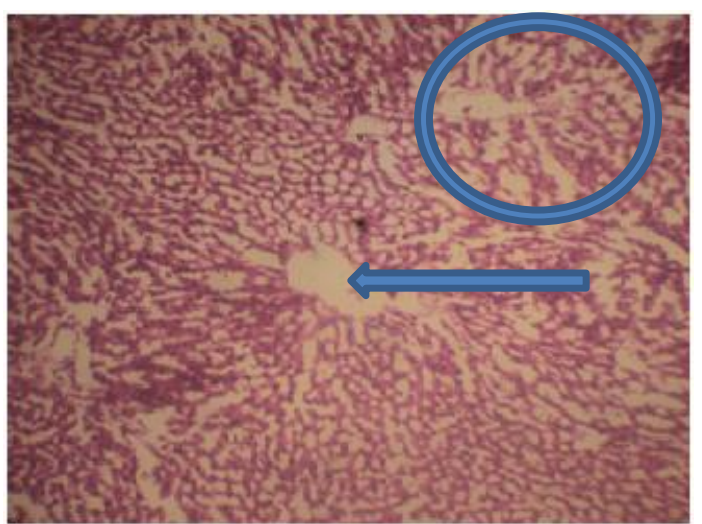

Plate 9a: Photomicrograph of liver of rat administered $500 \mathrm{mg} / \mathrm{kg}$ b. wt. of processed Calabash chalk $(\times 100)$. Central vein dilatation with cellular hyperplasia

\section{Discussion}

The mineral contents of processed (PCC) and unprocessed calabash chalk (UCC) samples are similar except zinc that is found in unprocessed but absent in processed sample. The quantities of these minerals in the two samples differ, with the PCC having higher quantity of detected minerals except for iron and phosphorus. The type and quantity of these minerals in the samples may depend on the soil or geographical location from which the calabash chalk was obtained (Nurnadi et al., 2013). The elevated level of sodium in processed calabash chalk compared to that of unprocessed can also be related to the method of preparation (salting).

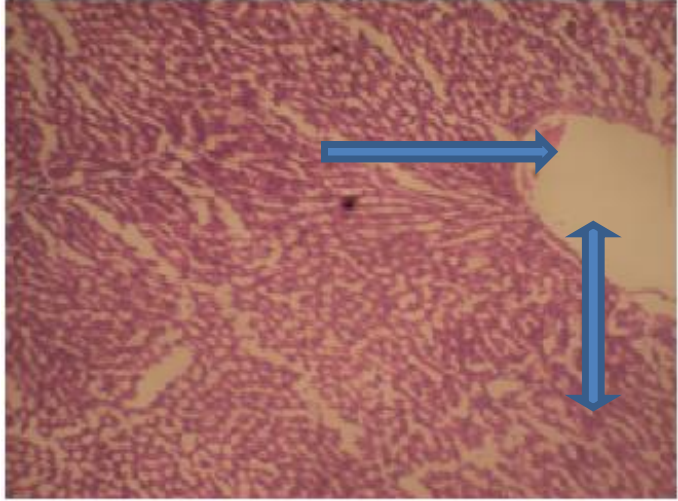

Plate 8b: Photomicrograph of liver of rat administered $250 \mathrm{mg} / \mathrm{kg}$ b.w of unprocessed Calabash chalk (x100). Moderate dilatation of central veins and sinusoids, with cellular hyperplasia

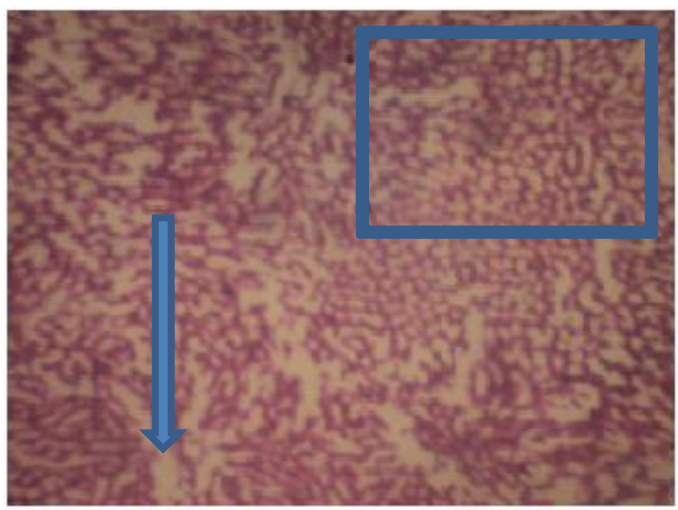

Plate 9b: Photomicrograph of the liver of rat administered $500 \mathrm{mg} / \mathrm{kg}$ b. wt. of unprocessed Calabash chalk ( $\times 100)$. Severe distortion of liver parenchyma with dilatation of sinusoids is observe

preparation (salting). Also, concentration of the minerals may be elevated as a result of contamination from agricultural or industrial waste (Ekong et al., 2012). Some of the minerals present in calabash chalk may be released in the gut after exposure to digestive fluids and have nutritional benefit, but studies have shown that some edible clay may absorb or bind to minerals such as potassium and iron in the gut leading to hypokalemia and iron deficiency anaemia (Vermeer and Ferrell, 1985). Both samples of calabash chalk used in this study do not contain heavy metals such as arsenic, chromium and lead. This is contrary to previous report by Nurnadi et al. (2013) where heavy metals 
were detected in the edible clay used in their study.

Measurement of the activity of enzymes is an indispensable tool in the assessment of cellular toxicity caused by chemical compounds including plant extracts (Yakubu et al., 2003). Such measurement can also be used to indicate tissue cellular damage caused by a chemical compound long before it is revealed by histological techniques (Akanji, 1986).

The level of aspartate aminotransferase is related to the proportion of cells affected by disease or injury, and also depends on length of time of injury (Prabodh et al., 2012). An increase in the serum AST activity at all doses of calabash chalk (processed and unprocessed) suggests damage to the plasma membrane which could lead to the leakage of the enzyme into the plasma via extracellular fluids (Malbica and Hart, 1971). This is further supported by the corresponding increased activities recorded in the liver at 500 $\mathrm{mg} / \mathrm{kg} \mathrm{b}$. wt and kidney at 250 and $500 \mathrm{mg} / \mathrm{kg} \mathrm{b}$. wt. except for the unprocessed at $500 \mathrm{mg} / \mathrm{kg} \mathrm{b}$. wt. of the chalk. Kim et al. (2008) have reported that in acute hepatocellular injury, serum AST levels usually rise immediately, reaching a higher level than ALT initially due to the higher activity of AST in hepatocytes and its release with liver injury. Thus, the liver and kidney integrity might have been compromised.

Alanine aminotransferase is involved in the transfer of amino groups from a-amino acid to aketo acid and in the biochemical regulation of intracellular amino acid pool. ALT activities are increased in the plasma in conditions in which cells are damaged or dead (Jimoh and Odutuga, 2001). Processed and unprocessed Calabash chalk did not produce any significant change in ALT activity in the serum, liver and kidney, suggesting that the samples did not cause any significant change in metabolic activities catalysed by alanine aminotransferase. Gamma glutamyl transferase (GGT) is found in the liver where it plays a key role in the gamma-glutamyl cycle, a pathway for the synthesis and degradation of glutathione and degradation of glutathione and xenobiotic detoxification (Siest et al., 1992). The significant reduction observed at $500 \mathrm{mg} / \mathrm{kg}$ b.w doses of both samples suggests that the integrity of the membrane of cells in the liver and kidney may have been adversely affected at this high dose.

Alkaline phosphatase is used to assess the integrity of plasma membrane and endoplasmic reticulum (Akanji et al., 1993), such that any alteration in the activity of the enzyme in the tissue and serum would indicate likely damage to the plasma membrane (Yakubu, 2006).

A decrease in the activity of ALP following the administration of $150 \mathrm{mg} / \mathrm{kg}$ b.wt dose and 250 $\mathrm{mg} / \mathrm{kg}$ bwt dose of processed and unprocessed calabash chalk may be due to the inactivation of the enzyme molecule by calabash chalk or inhibition of the enzyme activity at the cellular level. Higher activities at $500 \mathrm{mg} / \mathrm{kg}$ b.wt compared to other doses of the chalk may be due to increased synthesis and release of the enzyme from the plasma membrane due to assault by the chemical and is an indication of malfunction or blockage of the liver, bile ducts or gallbladder system (Kaslow, 2016). Histological examination of tissues could serve as complementary evidence to enzyme studies by revealing any distortion/damage to the normal structure of the tissue. The significant changes in kidney histology at all the doses compared to the control, except $150 \mathrm{mg} / \mathrm{kg}$ b.w of processed calabash chalk may due to bioaccumulation and toxic effects of some components like manganese, copper, zinc in the Calabash chalk. Manganese has been implicated in severe renal disease of male rats treated with high manganese Ponnakkam et al. (2003) and copper and zinc salts are capable of producing severe damage in gills and necrotic changes in the liver and kidney Rojik et al. (1983).

The liver is essential for the detoxification of metabolic waste products, drugs and toxins. The moderate dilatation of central vein and sinusoids with varying degree of cellular hyperplasia produced by higher degree doses (250 and 500 $\mathrm{mg} / \mathrm{kg}$ b.w) of calabash chalk (processed and unprocessed is also an indication of toxicity of the chalk. The result corroborate the effect of the chalk on liver enzymes and agreed with the report 
Ekong et al. (2008), on differential effects of calabash chalk on the histology of the liver of adult wistar rats in which $40 \mathrm{mg} / \mathrm{kg}$ of non-salted Calabash chalk showed fragmentation of the parenchymal cells, with few hexagonal lobules and dilated sinusoids.

\section{Conclusion}

The results of this study show that administration of processed and unprocessed Calabash chalk (Nzu) at doses of 250 and 500 $\mathrm{mg} / \mathrm{kg}$ body weight produced significant increase in AST levels in liver and kidney and also caused significant histological changes in the liver and kidney which suggest possible adverse reaction of calabash chalk at these doses. This study therefore suggests that processed and unprocessed Calabash chalk are unsafe for oral consumption.

\section{References}

Abrahams, P. W., Davies, T. C., Solomon, A. O., Trow, A. I., and Wragg, J (2013). Human geophagia, calabash chalk and undongo: mineral element nutritional implication. PLoS One. 8(1): e53304.

Akanji, M. A. (1986). A comparative biochemical study of the interaction of some 18 trypanocides with rat tissue cellular system. Ph.D thesis, University of Ife, IleIfe.

Akanji, M. A., Olagoke, O. A., and Oloyede, O. B. (1993). Effect of chronic consumption of metabisulphite on the integrity of rat kidney cellular system. Toxicology. 8:173179

Alexander, M. D., Wodwodt, A. and Akos-Kiss, F. C. S. (2002). Geophagia: the history of earth - eating. Journal of the Royal Society of Medicine. 95 (3):143-146.

Bisi-Johnson, M. A., Obi, C. L. and Ekosse, G. E. (2010). Microbiological and health related perspectives of geophagia: an overview. African Journal of Biotechnology. 9(19):5784-5791.
Dean, J. R., Deary, M.E., Gbefa, B. K. and Scott, W. $C$. (2004). Characterisation and analysis of persistent organic pollutants and major, minor and trace elements in Calabash chalk. Chemosphere. 57(1):21-25.

Ekong, M. B., Ekanem, T. B., Sunday, A. O., Aquaisua, A. N. and Akpanabiatu, M.I. (2012). "Evaluation of calabash chalk effect on femur bone morphometry and mineralization in young Wistar rats: a pilot study," International Journal of Applied Basic and Medical Research. 2(2); 107-110

Ekong, M. B., Akpantah, A. O., Ibok, O. S., Eluwa, M. A., and Ekanem, T. B. (2008). "Differential effects of calabash chalk on the histology of liver of adult Wistar rats," The Internet Journal of Health, 8(2): 30-7

Ferrell, R. E. (2008). "Medicinal clay and spiritual healing". Clays and Clay Minerals. 56 (6): 751-60.

Food Standards Agency (2003) Calabash chalk warning. Available from:http://www.food.gov.uk/foodindustry /imports/banned_restricted/calabashchal $\mathrm{k}$

Health Canada (2007). Calabash chalk may pose health risk for pregnant and breastfeeding women. Available from: http://www.hcsc.gc.ca/ahc-asc/media/advisoriesavis/_2007/2007_136-eng.php

Jimoh, F. O. and Odutuga, A. A. (2001). Changes in the activities of some diagnostic enzymes in some rat tissues following the consumption of thermally oxidized groundnut oil. Nigerian Journal of Biochemistry and Molecular Biology 16:173- 176

Kaslow, J. E. (2016).Alkaline phosphatase. http://www.drkaslow.com/html/alkaline_ph osphatase.html

Kim, W. R., Flamm, S. L., Di Bisceglie, A. M. and Bodenheimer, $H$. C.Jr (2008) Serum Activity of Alanine Aminotransferase(ALT) as an Indicator of Health and Disease. Hepatology, 47: 4. 
Fountain Journal of Natural and Applied Sciences: 2016; 5(1): 1 - 11

Krause, W. J. (2001). The Art of Examining and Interpreting Histological Preparations. A Student Handbook. The Parthenon Publishing Group, New York, London. 17680.

Malbica, J. O. and Hart, L. G. (1971). Effect of adenosine triphosphate and some antiinflammatory agents on purified fraction having high acid phosphatase and labile glucoronidase activity. Biochemical Pharmacology. 20: 2017-2022.

Mcloughlin, I. J. (2002). The picas. British Journal of Hospital Medicine 37:286-290.

Nurnadi, A. A., Azrina, A., Amin, I., Mohd-Yunus, A. S., MohdIzuan, E. H. (2013). Mineral contents of selected marine fish and shellfish from the west coast of peninsular Malaysia. International Food Research Journal. 20(1):431-437.

Organization for Economic Cooperation and Development (OECD) guideline 423 (2001) Oral Toxicity Study in Rodents. OECD guideline for the testing of chemicals. 423:1-8.

Organization for Economic Cooperation and Development (OECD) guideline 407 (2006).

Repeated dose 28-day oral toxicity study in rodents. OECD guideline for the testing of chemicals. 407:1-8.

Prabodh, V., Deva, P., Godi, S., Yeruva, R., Nadella, C. and Sripada, D. (2012). Importance of Cardiac Marker Enzymes (Aspartate Transaminase and Troponin I) in Acute Myocardial Infarction: A Case-Control Study from South India. International Journal of Medical Science and Public Health 1:118-120

Ponnakkam, T. Iszard, M. and Henry, G. (2003). Effect of oral administration of manganese on the kidneys and urinary bladder of Sprague-Dawley rats. International Journal of Toxicology. 22(3): 227-32.

Reitman, S. and Frankel, S. (1957). A colorimetric method for the determination of serum glutamic oxaloacetate and pyruvate transaminase. America Journal of Clinical pathology 28:36- 63

Rojik, I., Nemcsók, J. and Boross, L. (1983) Morphological and biochemical studies on liver, kidney and gill of fishes affected by pesticides. Acta Biologica Hungarica 34(1):81-92

Schmidt E, Schmidt FW. 1963. Determination of serum glutamic oxaloacetic and glutamic pyruvic transaminase. Enzyme Biological Clinic 3:1-5.

Siest, G., Courtay, C., Oster, T., Michelet, F., Visvikis, A. and Diederich, M. (1992). "Gamma-glutamyltransferase: nucleotide sequence of the human pancreatic CDNA. Evidence for a ubiquitous gammaglutamyltransferase polypeptide in human tissues". Biochemical Pharmacology. 43 (12): 2527-2533.

Szasz G. (1969). A kinetic photometric method for serum gamma glutamyltranspeptidase. Clinical Chemistry. 15(2):124-136

Vermeer, D. E., Ferrell, R. E. (1985). Nigerian geophagical clay: a traditional antidiarrheal Pharmaceutical. Science. 227(4687):634636.

Williams, L. B., Haydel, S. E. and Ferrell, R. E. (2009). "Bentonite, Bandaids, and Borborygmi". Elements. 5(2): 99-104.

Wright, P. J., Leathwood, P. D. and Plummer, D. T. (1972). Enzymes in rat urine. Alkaline phosphatase. Enzymologia. 42:317-327.

Yakubu, M. T., Bilbis, L. S., Lawal, M., and Akanji, M. A. (2003). Effect of Repeated Administration of sildenafl citrate on selected enzyme activities of liver and agretis stem in male albino rats. Ph. D. Thesis, University of Ilorin, Nigeria..

Yakubu, M. T. (2006). Aphrodisiac and toxicological potentials of aqueous extract of Fadogia agretis stem in male albino rats. Ph. D. Thesis, University of Ilorin, Nigeria. 